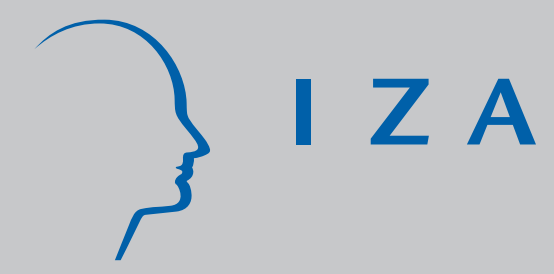

IZA DP No. 446

\title{
Macroeconomic Policy Lessons of Labor Market
} Frictions

Eran Yashiv

March 2002 


\title{
Macroeconomic Policy Lessons of Labor Market Frictions
}

\author{
Eran Yashiv \\ Tel Aviv University, CEPR and IZA, Bonn
}

\author{
Discussion Paper No. 446 \\ March 2002
}

\author{
IZA \\ P.O. Box 7240 \\ D-53072 Bonn \\ Germany \\ Tel.: +49-228-3894-0 \\ Fax: +49-228-3894-210 \\ Email: iza@iza.org
}

This Discussion Paper is issued within the framework of IZA's research area Evaluation of Labor Market Policies and Projects. Any opinions expressed here are those of the author(s) and not those of the institute. Research disseminated by IZA may include views on policy, but the institute itself takes no institutional policy positions.

The Institute for the Study of Labor (IZA) in Bonn is a local and virtual international research center and a place of communication between science, politics and business. IZA is an independent, nonprofit limited liability company (Gesellschaft mit beschränkter Haftung) supported by the Deutsche Post AG. The center is associated with the University of Bonn and offers a stimulating research environment through its research networks, research support, and visitors and doctoral programs. IZA engages in (i) original and internationally competitive research in all fields of labor economics, (ii) development of policy concepts, and (iii) dissemination of research results and concepts to the interested public. The current research program deals with (1) mobility and flexibility of labor, (2) internationalization of labor markets, (3) the welfare state and labor markets, (4) labor markets in transition countries, (5) the future of labor, (6) evaluation of labor market policies and projects and (7) general labor economics.

IZA Discussion Papers often represent preliminary work and are circulated to encourage discussion. Citation of such a paper should account for its provisional character. A revised version may be available on the IZA website (www.iza.org) or directly from the author. 
IZA Discussion Paper No. 446

March 2002

\section{ABSTRACT \\ Macroeconomic Policy Lessons of Labor Market Frictions}

The paper explores the consequences of macroeconomic policy for labor market outcomes in the presence of frictions. It shows how policy may be useful in overriding frictions, as well as how it might generate adverse outcomes. The analysis looks at the main tools of macroeconomic policy and pertains to both the non-stochastic steady state and to business cycle fluctuations. A partial-equilibrium, empirically-grounded model is used to simulate policy effects. It relies on a reduced-form VAR of the actual data to specify the stochastic behavior of exogenous variables, precluding the possibility that labor market results will be affected by misspecifications in other parts of a more general macroeconomic model.

The key results are that policy has effects on the stochastic behavior of key variables measures that reduce unemployment also reduce its persistence and increase the volatility of vacancies. Hiring subsidies and unemployment benefits have substantial effects on labor market outcomes, while employment subsidies or wage tax reductions are not very effective policy instruments.

JEL Classification: E24, E32

Keywords: Macroeconomic policy, labor market frictions, business cycles, Beveridge curve, natural rate of unemployment

Eran Yashiv

Berglas \#226

Tel Aviv University

Tel Aviv 69978

Israel

Tel.: +972-3-640 9233

Fax: +972-3-640 9908

Email: yashiv@post.tau.ac.il

\footnotetext{
* I have benefited from useful comments by two anonymous referees, Dani Tsiddon, Michel Strawcyznski and seminar participants at the Hebrew University and Tel Aviv University. I am grateful to Michael Ornstein for research assistance. Any errors are my own.
} 


\section{Macroeconomic Policy Lessons of Labor Market Frictions}

\section{Introduction}

The importance of the role of labor market frictions in aggregate fluctuations is increasingly recognized. ${ }^{1}$ Much attention has also been given to movements in the 'natural rate of unemployment,' a concept which is closely linked to the existence of frictions. It has been argued that government policy may have an effect on this equilibrium rate; for example, several authors have claimed that the implementation of certain policies explain, at least partially, high unemployment rates in Europe. ${ }^{2}$ This paper explores the labor market consequences of macroeconomic policy in the presence of frictions. It seeks to address the following questions: given frictions, how does government policy affect key labor market outcomes in the steady state and what effects does it have on their business cycle properties. More specifically, the paper explores the decline in unemployment following the implementation of different policy measures, the "cost-effectiveness" of each measure, and the changes in the stochastic behavior of unemployment and other key outcomes that follow each policy.

The paper models labor market frictions as costly search and job-worker matching processes. The analysis shows how policy may be useful in overriding these frictions and how it might generate adverse outcomes. A stochastic, discrete-time version of the search and matching model is used for this purpose. The model is solved for the non-stochastic steady state analytically and for equilibrium dynamics (the dynamic path and business cycle fluctuations) numerically. The idea is to give both qualitative answers - identify the mechanisms that are in operation when a policy measure is introduced and quantitative answers - by how much does a given policy measure change labor market outcomes. The macroeconomic policy measures examined include hiring subsidies, employment subsidies, wage taxes, and unemployment benefits. These measures are comparable in terms of government expenditures and the results are used to evaluate policy effectiveness. The analysis shows how budget constraints may be used to solve for the value of policy instruments given firms' optimization and the structure of the market.

Much of the existing analysis in this framework has focused on the steady

\footnotetext{
${ }^{1}$ See the discussion in the recent surveys by Hall (1999) and by Mortensen and Pissarides (1999a) and references therein.

${ }^{2}$ See, for example, Krugman (1994) and the papers collected in Snower and de la Dehesa (1997).
} 
state. ${ }^{3}$ In papers that presented numerical estimates, key calibrated values were often assumed or roughly deduced from stylized facts. The innovation of the current analysis is twofold: first, it relates to business-cycle dynamics in addition to the steady-state. Thus the paper shows how policy influences the adjustment of the economy following a shock by deriving the implications with respect to the volatility and cyclicality of all key labor market outcomes. Second, the analysis is empirically-grounded, based on Israeli labor market data which have proved to be particularly well-suited to study labor market frictions, with time series that match the model's definitions of the relevant variables. The model is calibrated and simulated with reference to structural econometric estimates. The analysis is The dynamic analysis is undertaken using a reduced-form VAR of the actual data to specify the stochastic behavior of exogenous variables. This "agnostic" approach precludes the possibility that labor market results will be affected by misspecifications in other parts of a more general macroeconomic model.

Beyond policy implications, an additional interpretation of the analysis is that it provides a tool to assess the effects of varying the amount of frictions. Thus, it shows how frictions of different degree affect the behavior of labor market variables along the cycle and in the steady state. It also bears some consequences for the analysis of U.S.-European unemployment differences. For example, one finding pertains to economies with laws and bureaucratic procedures that make hiring effectively more costly - such as some of the European countries. The analysis implies that these economies, compared to those without such laws and procedures, should expect a higher rate of unemployment with longer duration and more persistence, and with all key variables less volatile and less cyclical.

The paper proceeds as follows: Section 2 presents the model of the aggregate labor market with frictions, relegating technical derivations to an appendix. Section 3 discusses the data and the calibration of the model, showing how the model fits the data. Section 4 reports the effects of the policy measures, including discussion of policy effectiveness and the implications of budget constraints. Section 5 concludes.

\section{The Model}

This section presents the model of the aggregate labor market with frictions. Frictions refer to search costs and to the time-consuming matching

\footnotetext{
${ }^{3}$ See the survey by Mortensen and Pissarides (1999a). Some important contributions are the analyses of Millard and Mortensen (1997), Mortensen and Pissarides (1999b) and Pissarides (1998, 2000 chapter 9).
} 
process. It builds upon the Diamond-Mortensen-Pissarides model,${ }^{4}$ casting the analysis in stochastic, discrete-time terms. Sub-section 2.1 describes the environment, sub-section 2.2 defines the equilibrium, and 2.3 presents the resulting dynamics and steady state. The section ends with a graphical representation of the model (2.4). The description is brief; for a more extensive treatment see Yashiv (2000a) or the cited references.

\subsection{The Environment}

M atching Technology. Workers looking for jobs and firms looking for workers are faced with frictions such as different locations leading to regional mismatch or lags and asymmetries in the transmission of information. These frictions are embedded in the concept of a matching function which produces hires out of vacancies and unemployment, leaving certain jobs unfilled and certain workers unemployed. It satisfies the following properties:

$$
\begin{aligned}
M_{t} & =\widetilde{M}\left(U_{t}, V_{t}\right) \\
\frac{\partial \widetilde{M}}{\partial U} & >0, \quad \frac{\partial \widetilde{M}}{\partial V}>0, M_{t} \leq \min \left(U_{t}, V_{t}\right)
\end{aligned}
$$

where $U$ is the stock of unemployed workers, $V$ is the stock of vacancies and $M$ is the flow of hires from unemployment to employment.

Firms' Objectives. Firms maximize the expected, discounted present value of profits (where all other factors of production have been "maximized out"):

$$
\max _{\left\{V_{t}\right\}_{t=0}^{\infty}} E_{0} \sum_{t=0}^{\infty}\left(\prod_{j=0}^{t} \beta_{j}\right)\left[\left(F_{t}-W_{t} N_{t}+\tau_{N} F_{t}-\Gamma_{t}\right)\right]
$$

where $\beta_{j}=\frac{1}{1+r_{j}}$ and $r$ is the rate of interest, $F$ is output, $W$ is the real wage, $N$ is the employment stock and $\Gamma$ denotes hiring costs. An employment subsidy is postulated as $\left(\tau_{N} \frac{F_{t}}{N_{t}}\right) N_{t}=\tau_{N} F_{t}$ with $0 \leq \tau_{N}<1 .{ }^{5} \mathrm{~A}$ hiring subsidy affecting $\Gamma$ is introduced below.

This maximization is subject to the employment dynamics equation given by:

\footnotetext{
${ }^{4}$ Key contributions were made by Diamond (1982a,b), Mortensen (1982) and Pissarides (1985). For recent surveys see Mortensen and Pissarides (1999a) and Pissarides (2000).

${ }^{5}$ This formulation makes total subsidy payments increase at the rate of growth of the economy.
} 


$$
N_{t+1}=N_{t}(1-\delta)+Q_{t} V_{t}
$$

where $Q_{t}=\frac{M_{t}}{V_{t}}$ and workers are assumed to be separated from jobs at an exogenous rate $\delta .^{6}$

Wage Determination. The wage is determined by the Nash solution to the following bargaining problem:

$$
W_{t}=\arg \max \left(J_{t}^{N}-J_{t}^{U}\right)^{\xi}\left(J_{t}^{F}-J_{t}^{V}\right)^{1-\xi}
$$

where $J^{N}$ and $J^{U}$ are the present value for the worker of employment and unemployment respectively; $J^{F}$ and $J^{V}$ are the firm's present value of profits from a filled job and from a vacancy respectively; and $0<\xi<1$ reflects the degree of asymmetry in bargaining. Workers pay a wage tax at rate $0 \leq \tau_{W} \leq 1$. In this equilibrium set-up, the analysis would not change if these taxes were levied on firms.

Relying on the empirical results in Yashiv (2000b), the value of unemployment, to be denoted $b$, is formalized as follows:

$$
b_{t}=z \frac{F_{t}}{N_{t}}+\rho\left(1-\tau_{W}\right) W_{t}
$$

The first term captures the value of home production or any non-pecuniary income and is assumed proportional to average (or marginal) output with a parameter $z$. The second term captures unemployment benefits with the gross replacement ratio denoted $\rho$; benefits are taxed at the rate $\tau_{W} \cdot{ }^{7}$

Exogenous shocks. The model has three exogenous variables that are determined in other markets. These are productivity growth $\left(G^{X}\right)$, labor force growth $\left(G^{L}\right)$, and the discount factor $(\beta)$. It is these variables that inject shocks into the system. Intentionally, the underlying structural shocks are not formulated. Instead, it is postulated that these exogenous variables (in terms of $\log$ deviations from their non-stochastic steady state values) follow a first-order VAR. Using the notation $\widehat{Y}_{t}=\frac{Y_{t}-Y}{Y} \approx \ln Y_{t}-\ln Y$ for any variable $Y_{t}$, where $Y$ is the steady-state value, this is given by:

\footnotetext{
${ }^{6}$ The assumption of a constant match separation rate $\delta$ is a good approximation in the Israeli economy. The separation rate series has no trend and is stationary around its average value (4 percent a quarter).

${ }^{7}$ This benefit tax scheme is true for the Israeli economy. Quantitative analysis of a differential unemployment benefits tax rate yielded results that are similar to changing $\rho$ and so are not reported.
} 


$$
\left[\begin{array}{c}
\widehat{G}_{t+1}^{X} \\
\widehat{G}_{t+1}^{L} \\
\widehat{\beta}_{t+1}
\end{array}\right]=\Pi\left[\begin{array}{c}
\widehat{G}_{t}^{X} \\
\widehat{G}_{t}^{L} \\
\widehat{\beta}_{t}
\end{array}\right]+\Sigma
$$

In Section 4 below reduced-form VAR estimates of the actual data are used to quantify the coefficient matrix $\Pi$ and the variance-covariance matrix of the disturbances $\Sigma$. Thus the current model takes an "agnostic approach" to the sources of the shocks, which is consistent with models that emphasize demand shocks as well as with models that emphasize technology shocks.

In what follows all labor market variables are cast in terms of rates out of the labor force $(L)$ and all relevant variables are divided by the average output $\left(\frac{F}{N}\right)$. This leaves a system that is stationary and is affected by the afore-cited shocks.

\subsection{Equilibrium}

Firms solve their constrained maximization problem (equations 2 and 3) to determine the amount of vacancies $(V)$ to open; this is done subject to the evolution of productivity and the rate of interest, as given by (6); the matching function (1) yields a flow of hires out of stocks of vacancies and unemployed workers; together with the separation rate $\delta$ and with labor force growth, given by (6), it generates changes in the stock of employment (and unemployment) according to (3); once matched, bargaining between firms and workers yields a wage solution (4). In this partial equilibrium, the stocks $U$ (and $N$ ) and $V$, the flow of hiring $M$, and the wage $w$ are determined. Consequently the matching rate $Q$ is determined. This solution obtains given marginal productivity $\frac{\partial F_{t}}{\partial N_{t}}$, the interest rate $r_{t}$, the separation rate $\delta$, the policy variables (unemployment benefits, wage taxes and employment and hiring subsidies) and the initial values of $U, N$ and $V$.

\subsection{Model Solution: the Dynamic System and the Steady State}

In order to fully characterize the model the firms' problem and the wage bargaining problem are solved (2.3.1). Subsequently the non-stochastic steady state (2.3.2) and the dynamics (2.3.3) are derived. 


\subsubsection{Firms' F.O.C and Wage Solution}

The F.O.C of problem (2)-(3) are (where $\Lambda$ is the discounted Lagrange multiplier):

$$
\begin{gathered}
\frac{\partial \Gamma_{t}}{\partial V_{t}}=Q_{t} E_{t} \Lambda_{t} \\
E_{t} \Lambda_{t}=E_{t} \beta_{t+1}\left[\frac{\partial F_{t+1}}{\partial N_{t+1}}\left(1+\tau_{N}\right)-W_{t+1}-\frac{\partial \Gamma_{t+1}}{\partial N_{t+1}}\right]+E_{t}(1-\delta) \beta_{t+1} \Lambda_{t+1}
\end{gathered}
$$

as well as equation (3) and the relevant transversality condition.

The first, intratemporal condition (equation 7) sets the marginal cost of hiring $\frac{\partial \Gamma_{t}}{\partial V_{t}}$ equal to the expected value of the multiplier times the probability of filling the vacancy. The second, intertemporal condition (equation 8) sets the multiplier equal to the sum of the expected, discounted marginal profit in the next period $E_{t} \beta_{t+1}\left[\frac{\partial F_{t+1}}{\partial N_{t+1}}\left(1+\tau_{N}\right)-W_{t+1}-\frac{\partial \Gamma_{t+1}}{\partial N_{t+1}}\right]$ and the expected, discounted (using also $\delta$ ) value of the multiplier in the next period $E_{t}(1-$ б) $\beta_{t+1} \Lambda_{t+1}$.

The wage solution is given by (see Pissarides (2000) for the derivation): ${ }^{8}$

$$
W_{t}=\eta\left(\frac{\partial F_{t}}{\partial N_{t}}\left(1+\tau_{N}\right)-\frac{\partial \Gamma_{t}}{\partial N_{t}}+E_{t} P_{t} \Lambda_{t}\right)+\omega z \frac{F_{t}}{N_{t}}
$$

\subsubsection{The Non-Stochastic Steady State}

The non-stochastic steady state is characterized by two key relations. First, the rate of vacancy creation - based on the steady state form of (7) and (8) - is given by:

$$
\frac{\frac{\partial \Gamma}{\partial V}}{\frac{F}{N}}=Q \lambda=Q \frac{G^{X} \beta}{1-G^{X} \beta(1-\delta)} \pi
$$

This equation is set in terms of average output. The LHS are marginal costs; the RHS is the probability of filling a vacancy $(Q)$ times the asset value of

${ }^{8}$ where:

$$
\begin{gathered}
\eta \equiv \frac{\xi}{1-(1-\xi) \rho} \\
\omega \equiv \frac{(1-\xi)}{\left[\left(1-\tau_{W}\right)-(1-\xi) \rho\left(1-\tau_{W}\right)\right]}
\end{gathered}
$$


the match in the steady state $\left(\lambda=\frac{\Lambda}{F / N}\right)$. This value is the product of perperiod marginal profits, denoted $\pi^{9}$, and a discount factor $\Phi=\frac{G^{X} \beta}{1-G^{X} \beta(1-\delta)}$ that takes into account the real rate of interest, the rate of separation and productivity growth.

The second key steady-state relation relates to equilibrium labor market flows. These are derived from equating the rate of increase in employment with the rate of separation and increase in the labor force [inserting (1) into the steady state version of (3)]:

$$
\delta+G^{L}-1=\frac{M}{N}=\mu\left(\frac{U}{N}\right)^{\sigma}\left(\frac{V}{N}\right)^{1-\sigma}
$$

where $G^{L}$ is the gross rate of labor force growth.

From this equation the rate of unemployment in equilibrium, the natural rate, is given by:

$$
\frac{U}{L}=\frac{\delta+\left(G^{L}-1\right)}{\delta+\left(G^{L}-1\right)+P}
$$

where:

$$
L=N+U ; \quad P=\frac{M}{U}
$$

Equations (10) and (11) shall be at the heart of the analysis of the steady state.

\subsubsection{The Dynamic System}

Two aspects of the dynamics will be studied: (i) the dynamic path of the endogenous variables, when all exogenous variables are at their steady state level (i.e. non-stochastic dynamics) and (ii) stochastic steady-state dynamics, which capture business cycle fluctuations. To do so the model is solved numerically.

Log-linear approximation of equations (3), (7), and (8) around the steady state yields the following first-order linear difference equation system, where all variables are in terms of log deviations from steady state (see Appendix A):

$$
{ }^{9} \text { where } \pi=\frac{\left[\begin{array}{l}
\widehat{n}_{t+1} \\
\hat{\lambda}_{t+1}
\end{array}\right]}{=\frac{\left[\frac{\frac{\partial F_{t}}{\partial N_{t}}}{F / N}\left(1+\tau_{N}\right)-\frac{\frac{\partial \Gamma}{\partial N}}{F / N}\right](1-\eta)-\omega z}{1+\eta P \Phi}}
$$


where $B$ and $C$ are matrices of coefficients, which are complicated functions of the system's parameters and steady state values, and $n=\frac{N}{L}$.

The system is defined in terms of the endogenous state variable (the employment rate, $\widehat{n}_{t}$ ) and the co-state variable (the asset value of the match, $\widehat{\lambda}_{t}$ ) and the three exogenous variables (productivity growth, $\widehat{G}_{t+1}^{X}$, labor force growth $\widehat{G}_{t+1}^{L}$ and the discount factor $\left.\widehat{\beta}_{t+1}\right)$. The other variables of interest the firms' control variable $\left(\widehat{v}_{t}\right.$, the vacancy rate) and the other endogenous state variables $\left(\widehat{u}_{t}, \widehat{P}_{t}, \widehat{Q}_{t}, \widehat{m}_{t}\right)-$ are functions of the above variables. The solution of (14) allows for the derivation of the dynamic path and the stochastic dynamics, as explained in Appendix A. The properties of the system in terms of stability and dynamic paths are determined by the relevant eigenvalues. For plausible values of the parameters and steady state values - as discussed in Section 3 below - the system turns out to be a saddle, with a unique convergent path (see the appendix for the formal condition).

\subsection{Graphic Representation of Labor Market Equilib- rium}

Figure 1 represents the non-stochastic steady state of the model. Panel (a) illustrates the marginal hiring cost curve and the match asset value curve. Their intersection is the graphical expression of the F.O.C. (equation 10). Thus vacancy creation is at the point where the upward-sloping marginal hiring costs curve $\left(\frac{\frac{\partial \Gamma}{F}}{\frac{\partial V}{N}}\right)$ intersects the downward-sloping marginal match asset value curve $\left(Q \frac{G^{X} \beta}{1-G^{X} \beta(1-\delta)} \pi\right)$. Panel (b) shows the equilibrium in $\frac{U}{N}-\frac{V}{N}$ space: the upward sloping curve represents optimal vacancy creation (i.e. equation (10)) and the downward-sloping curve represents the steady-state flow relationship (equation 11). The latter is often labeled 'the Beveridge curve.'

Figure 1

\section{Baseline Model and Data Fit}

In this section the baseline model to be simulated for policy effects is derived. The data are discussed (3.1) and then the model is parameterized (3.2). Subsequently the data fit of this baseline model is evaluated (3.3). 


\subsection{The Data}

The analysis uses Israeli data and builds on structural estimates of the key relations in the model to set a baseline for quantitative analysis. The reason for looking at Israel is that its data are particularly well-suited to study labor market frictions, with time series that match the model's definitions of the relevant variables. Additionally, Yashiv (2000 a,b) has structurally estimated the search and matching model and found support for it in these data. These estimates are used below in the calibration-simulation analysis. The institutional set-up of the market, generating these data, is described in Yashiv (2000a) and the definitions and sources of the variables in Appendix B below.

\subsection{Baseline Model}

For production a standard Cobb-Douglas function is assumed:

$$
F_{t}=A_{t} N_{t}^{\alpha} K_{t}^{1-\alpha}
$$

where $A$ is technology and $K$ is capital.

Hiring costs refer to the costs incurred in all stages of recruiting: the cost of advertising, screening, training, and the cost of disrupting production. Relying on the empirical results in Yashiv (2000b), who tested alternative functional forms and variables to be included, the following formulation is used:

$$
\Gamma_{t}=\frac{\Theta\left(1-\tau_{\Theta}\right)}{1+\gamma}\left(\psi \frac{V_{t}}{N_{t}}+(1-\psi) \frac{M_{t}}{N_{t}}\right)^{1+\gamma} F_{t}, \quad 0 \leq \tau_{\Theta}<1
$$

where a hiring subsidy $\tau_{\Theta}$ is postulated; $\Theta$ is a scale parameter while $1+\gamma$ expresses the degree of convexity. Hiring costs are internal to production and hence are proportional to output $(F)$. They are increasing in a weighted average of the vacancy $\left(\frac{V_{t}}{N_{t}}\right)$ and hiring $\left(\frac{M_{t}}{N_{t}}\right)$ rates as part of the costs relates to vacancies, even if unfilled, and part to actual hires. The function is linearly homogenous in $V, M, N$ and $F$. It encompasses the cases of a fixed cost per vacancy and of increasing costs. When $\gamma=1$ (and there are no subsidies) the function reduces to a quadratic formulation $\left(\frac{\Theta}{2}\left(\psi \frac{V_{t}}{N_{t}}+(1-\psi) \frac{M_{t}}{N_{t}}\right)^{2} F_{t}\right)$ which is analogous to the standard formulation in "Tobin's q" models of investment where costs are quadratic in $\frac{I}{K}$.

Empirical work [previous work on Israeli data (Yashiv (2000a)), as well as work on other economies surveyed by Petrongolo and Pissarides (2001)] has shown that a Cobb-Douglas function with constant returns to scale is useful for parameterizing the matching function, i.e.: 


$$
M_{t}=\mu U_{t}^{\sigma} V_{t}^{1-\sigma}
$$

where $\mu$ stands for matching technology.

For the parameters the structural estimates reported in Yashiv (2000 a,b) are used to give numerical values to the parameters $\gamma$ and $\psi$ of the hiring cost function, the labor parameter in the production function $(\alpha)$, the worker's bargaining parameter $(\xi)$ and the unemployment elasticity $\sigma$ of the matching function. The scale parameters of the hiring cost function $(\Theta)$ and of the matching function $(\mu)$ are set so that the solution of the system will yield the steady state values of $\frac{U}{N}$ and $\frac{V}{N}$ discussed in the table's notes.

For the variables in steady state, data averages ${ }^{10}$ are taken or solved out of the steady state relations. ${ }^{11}$ Based on the data, the baseline has no hiring or employment subsidies $\left(\tau_{\Theta}=\tau_{N}=0\right)$, wage taxes $\left(\tau_{W}\right)$ are set at $28 \%$, and the replacement ratio $(\rho)$ at $0.4 .^{12}$

The methodology described in Appendix A below is used to derive the moments of the dynamic system. Panels (a)-(d) of Table 1 report the baseline values, all in quarterly terms. Panel (e) reports the statistics for the dynamic path in this baseline case.

\section{Table 1}

\subsection{The Fit of the Baseline Model}

How do the key variables behave stochastically and in particular what are their business cycle features? Panel (f) of Table 1 documents the co-movement, volatility and persistence in the data and as implied by the baseline model. The following sums up the features of the data and the performance of the model:

(i) The rate of employment (and unemployment) is highly persistent as evidenced by the auto-correlation $\rho\left(\widehat{n}_{t}, \widehat{n}_{t-1}\right)$ of 0.95 ; the model captures it well.

(ii) There is a negative correlation between unemployment and vacancies $\rho\left(\widehat{u}_{t}, \widehat{v}_{t}\right)$. This is the so-called "Beveridge curve." This moment too is captured by the model.

\footnotetext{
${ }^{10}$ Appendix B gives full definitions and sources of the data.

${ }^{11}$ See the notes to Table 1 for further details.

${ }^{12}$ The value of the wage tax is based on Table 6.10 in the CBS Annual Bulletin of Statistics, reporting household direct taxes and social security payments as a fraction of national income. For the replacement ratio National Insurance Agency and CBS data are used to divide the monthly average of nominal unemployment benefits per person by the average nominal wage for employee post in the business sector.
} 
(iii) There is virtually zero correlation between the rate of employment and the rate of productivity growth $\left(\rho\left(\widehat{n}_{t}, \widehat{G}_{t}^{X}\right)\right)$. This is an issue that has attracted much attention in the business cycle literature and is very well captured by the model.

The next two features are captured by the model but quantitatively not as well:

(iv) Vacancies are much more volatile than employment $\left(\frac{\operatorname{std} \widehat{v}}{\operatorname{std} \widehat{n}}\right.$ is high). Noting that vacancies in this model are akin to investment in labor, this point is reminiscent of the business cycle fact that investment in capital is highly volatile. The model generates volatile vacancies but not as volatile as the data indicate.

(v) Real unit labor costs (or the labor share of income, $s=\frac{W N}{F}$ ) are moderately pro-cyclical and more volatile than employment; the model's moments have the same signs but overstate their magnitude.

\section{Policy Effects}

In this section the effects of policy are simulated. First, the analysis examines comparable policy measures affecting all key variables in the steady-state, along the dynamic (saddle) path and in terms of business cycle dynamics (4.1). Subsequently policy effectiveness is evaluated with a comparison of the different measures (4.2). Finally, policy determination with budget constraints is considered (4.3).

\subsection{Effects on Labor Market Outcomes}

Table 2 quantifies the effects of policy by looking at changes in the policy parameters relative to the baseline. In all cases these parameters are permanently changed. In order to facilitate comparison between the different measures the analysis pertains to policy schemes that cost or generate revenues equal to $1 \%$ of output. ${ }^{13}$ There are four panels for the four policy schemes, each sub-divided into three sections. The first section reports the steady state values of all key variables. The second section reports the statistics of the non-stochastic dynamic path (the saddle path). The third section reports business cycle statistics, i.e. the co-movement, persistence and volatility statistics of the key variables. In each case, the value of the

\footnotetext{
${ }^{13}$ Throughout this analysis the baseline values of the parameters and exogenous variables are used, except for the policy parameter under study, and the moments of the dynamic system approximated around each steady state are derived.
} 
policy variable in question is reported in the top row. Each panel also reports the baseline case.

\section{Table 2}

\subsubsection{Hiring Subsidy}

Panel I shows the effects of a hiring subsidy that costs $1 \%$ of output $\left(\tau_{\Theta}=\right.$ $42.92 \%)$ and of a hiring $\operatorname{tax}\left(\tau_{\Theta}=-72.16 \%\right)$, which generates revenues equal to $1 \%$ of output. The essential effect of the subsidy is to shift down the marginal hiring cost curve and make it flatter. This is akin to the labor demand curve becoming flatter. In panel (a) of Figure 1 this is depicted by the movement from A to B. The subsidy has several effects: it lowers vacancy creation costs for firms thereby leading to more creation. Higher vacancy rates lead to lower unemployment (see panel (b) of Figure 1) and generate the well-known search externalities - the matching rate for firms $(Q)$ declines and that for workers $(P)$ increases. The rise in $P$ increases workers' wages and hence erodes firms' match profits. The asset value of the match declines because there is a decline both in the probability of filling a vacancy $(Q)$ and in per-period match profits $(\pi)$.

Section (a) of the table shows the effects on the non-stochastic steady state. Several results stand out: subsidy and tax of equal value generate asymmetric effects in absolute value due to the curvature of the hiring cost curve and of the Beveridge curve. These policy schemes generate significant changes in equilibrium unemployment, i.e. in the natural rate, with the subsidy bringing it down to a 'U.S.-type' level of $5.4 \%$ and the tax up to a 'European-type' level of $9.7 \%$. This result indicates that the frictions embodied in the hiring and training process are of substantial importance for steady-state unemployment. Subsidizing the firm with about $40 \%$ of the cost spent on every hire has several sizable effects: unemployment drops 1.8 percentage points and its duration declines from an average of about 21 weeks to 16 (as the matching rate, $P$, rises). Additionally, the gross wage as a fraction of income rises by 0.25 percentage points. The expected asset value of the match $(Q \Phi \pi)$ declines to about $65 \%$ of its initial value.

Section (b) shows that the subsidy policy makes the employment rate and consequently unemployment - less persistent along the saddle path and thus half of a given percentage deviation from steady state is eliminated after 3.1 quarters, as compared with 4.4 quarters in the baseline case. This is so because under the subsidy policy the vacancy rate responds more to changes in the expected value of the match, as the marginal cost curve becomes flatter. 
Moving to section (c) the same phenomenon is seen in stochastic terms: with a flatter curve, asset values $\lambda$ and consequently vacancies become even more volatile. It follows that vacancies react more to shocks and so employment and unemployment persistence declines. The negative $U-V$ relationship strengthens with this increased sensitivity. As these changes in $\lambda$ take place, the labor share $(s)$ which depends on it, becomes more pro-cyclical and more volatile. Note that a tax on hiring generates the opposite effects: vacancy creation becomes more "rigid" and so volatility declines and persistence increases. One implication of these results is that European countries, with laws and bureaucratic procedures that make hiring effectively more costly, should expect not only higher unemployment with longer duration, but also all key variables to be less volatile, more persistent, and less cyclical relative to an economy without these factors.

One critique of these results is that because the set-up of the model does not allow for endogenous separations (in particular, the firing of workers) there is a bias towards positive employment effects. Specifically, one possibility that is precluded here is that the separation rate will rise as the subsidy rises, thereby offsetting the positive effect on employment. This would mean that a subsidy will simultaneously engender more hiring and more firing. To see how restrictive is the assumption of a constant separation rate on the different labor market outcomes, the following exercise is conducted: the same hiring subsidy (i.e. $\tau_{\Theta}=42.92 \%$ ) is introduced as before, the separation rate is allowed to rise, and the baseline rate of unemployment is imposed, i.e. beneficial effects on employment are not allowed. This outcome can take place if the rate of separation rises sufficiently. Graphically, in terms of Figure 1, the following shifts happen when the separation rate rises and after the changes induced by the subsidy have already taken place: in panel (a) the marginal costs curve shifts up, as in equilibrium a higher proportion of vacancies are filled and hiring costs rise; the match asset value curve shifts down as the effective discount factor declines. Hence vacancy rates fall and asset values rise relative to the equilibrium with a subsidy $\tau_{\Theta}$ and a constant $\delta$. Consequently, in panel (b), the vacancy creation curve moves down and to the right. The Beveridge curve shifts out as higher matching flows are met with higher separation flows. As before, the responsiveness of vacancy rates to changes in profitability rises with the subsidy because, after all changes have taken place, the marginal cost curve is still flatter relative to the baseline. However this change is smaller than before as it is mitigated by the increase in the separation rate. This mitigating effect also reduces the variation in vacancy rates and in match asset values.

Numerically, the results are shown in the next to last column of Table 
2-I, with $\delta$ rising from $4.1 \%$ to $4.5 \% .^{14}$ The idea is to see what happens to all variables, except employment which is constrained to stay at its baseline. First, consider hiring behavior: in the new steady state relative to the baseline, vacancy creation is stimulated almost to the same level as with a constant $\delta$. Thus market tightness rises resulting in a higher $P$ and lower $Q$; the effects on these matching rates are now smaller than before due to the imposed constancy of $\frac{U}{L}$. The negative $U-V$ relationship strengthens, the half-life statistic drops from 4.4 quarters to 4.1 , and the persistence of unemployment declines from 0.970 to 0.968 . As indicated above, the volatility of vacancies falls. Second, consider the behavior of wages: in the steady state they fall rather than rise and so does their relative volatility. This is so mostly because of the increase in the discount rate generated by the higher separation rate, which reduces the present value of future match earnings.

There are two main conclusions. One is that there are effects to a hiring subsidy, even in the extreme case of a rise in separation rates that completely eliminates any employment gains. A second is that the analysis implies that policymakers can strengthen the effects of hiring subsidies by limiting the rise in separation rates (for example, through taxation of firing or other employment protection measures). The latter conclusion implies that in economies with firing constraints, hiring subsidies will be, ceteris paribus, more effective in reducing unemployment.

\subsubsection{Employment Subsidy}

The analysis examines a $1 \%$ employment subsidy $\left(\tau_{N}=1 \%\right)$ and a $1 \%$ employment $\operatorname{tax}\left(\tau_{N}=-1 \%\right)$. The essential effect of the subsidy is to increase match profits. In Figure 1 this is shown as the movement from $\mathrm{A}$ to $\mathrm{C}$ in Panel (a) and from A to B in panel (b). By increasing match profits the subsidy leads to more vacancy creation. Higher vacancy rates lead to lower unemployment and generate the same search externalities discussed above (the matching rate for firms declines and that for workers increases). Wages rise as both the subsidy $\tau_{N}$ and the matching rate $P$ rise. The increase in per-period profits and asset values is mitigated by the rise in wages. A $1 \%$ subsidy, while equal in terms of government outlays to the hiring subsidy, has small quantitative effects on all dimensions, as seen in Panel II of Table 2. The notable exception is the rise in the labor share of income $(s)$ which is bigger than in the hiring subsidy case. The reason is that the employment subsidy increases the surplus of the match and workers get part of this increase in the wage bargain. Wages rise also because of the increase in the

\footnotetext{
${ }^{14}$ This rise is solved for from the steady state conditions coupled with the restriction that $\frac{U}{N}$ will remain at its baseline value.
} 
workers' matching rate $(P)$. Match profits do rise, as the positive subsidy effect dominates the negative effect of the rise in wages, but the resulting increase is relatively small. Hence vacancy creation increases only slightly. The leak into wages is thus of crucial importance for the effectiveness of the subsidy. This leak depends on the wage bargaining parameter $\xi$. The table reports the effects on the key variables when varying this parameter, following the variation across estimation specifications reported in Yashiv (2000b). The two extremal points of this range are $\xi=0.1$ and $\xi=0.3 .{ }^{15}$ The conclusion is that the higher is $\xi$, the smaller is the effect of the subsidy, due to bigger leakage into wages. However, in any case, the effect is relatively small.

\subsubsection{Wage Tax}

Changes in the wage tax $\left(\tau_{W}\right)$ induce a direct effect on the worker share in the wage bargain. The relative value of the part of the reservation wage which is independent of the actual wage $\left(z \frac{F}{N}\right)$ changes when wages are taxed at a different rate. Lowering the tax rate lowers the workers' share, erodes the gross wage, and increases firms' match profits. This operates to enhance vacancy creation, leading to lower unemployment. In Figure 1, this can be seen again as a movement from $\mathrm{A}$ to $\mathrm{C}$ in Panel (a) and from $\mathrm{A}$ to $\mathrm{B}$ in panel (b). Like the employment subsidy case, a wage tax decline or increase equal to $1 \%$ of output has a small effect on labor market outcomes, as seen in panel III of Table 2. The decrease in taxation generates a decrease in unemployment persistence and a rise in the volatility of vacancies. Here too the value of $\xi$ matters: the lower is $\xi$, the more effective is tax reduction in generating decreases in unemployment. Once more the effects are small, relative to the hiring subsidies case, irrespective of the value of $\xi$.

\subsubsection{Unemployment Benefits}

Changing unemployment benefits $(\rho)$ is another policy measure which affects the wage. In order to reduce unemployment, the government needs to lower unemployment benefits, which involves a reduction in expenditures. The differences examined in panel IV of Table 2 are equal in value to $1 \%$ of output. A decrease in $\rho$ generates a reduction in wages as benefits determine the workers' threat point in the wage bargain. Hence there is an increase in match profits and in the asset value of the match. In Figure 1 this is a movement from A to C in panel (a) and from A to B in panel (b). Vacancy creation is enhanced, unemployment falls and its duration declines. Quantitatively the

\footnotetext{
${ }^{15}$ Note that in the dynamic analysis (sections $\mathrm{b}$ and $\mathrm{c}$ in the table) the baseline itself changes to reflect the modified value of $\xi$.
} 
effects are almost as substantial as the hiring subsidy case. Declining unemployment benefits lower the persistence of employment and increase the volatility of vacancies. These results too may explain U.S.-European unemployment differences, as European economies have much higher replacement ratios [see for example Chart 8.1 and Table 8.1 in OECD (1994, pp.174-175)]. In fact these differences are in the order of magnitude of the differences in $\rho$ (17\% vs. $53 \%$ ) and unemployment rates (about $6 \%$ vs. $9 \%$ ) reported here.

\subsection{Policy Effectiveness}

What is the effectiveness of each of the policy instruments described above in reducing unemployment? Table 3 - based on the computations of Table 2 - reports the outcome when each policy instrument, except for $\rho$, is used with outlays equal to $1 \%$ of output. The table shows the value of the policy instrument used to carry out the policy and the changes in the key variables in terms of percentage points.

\section{Table 3}

Note that in all cases unemployment declines as vacancy rates increase and thus $P$ increases and $Q$ falls. However, other variables, such as match asset values, do not move in the same direction, as can be seen by comparing the movement from $\mathrm{A}$ to $\mathrm{B}$ and from $\mathrm{A}$ to $\mathrm{C}$ in panel (a) of Figure 1. Hence half-life statistics and the moments of persistence and co-movement change differentially.

A key feature, which stands out from the table, is that hiring subsidies are much more effective than employment subsidies or changes in wage taxation. For the same government outlays unemployment declines by 1.8 percentage points in the hiring subsidies case, compared to a 0.1 percentage point decline in the other cases. For the other labor market outcomes the differences in effects are of similar order of magnitude.

Other differences between policy schemes pertain to the change in gross wages: a hiring subsidy induces a rise in the workers' matching rate thereby increasing wages; wages rise even more with an employment subsidy, because in addition to the matching rate increase there is also an increase in the match surplus. Gross wages decline with the decrease in the wage tax: while the matching rate increase has a positive effect on wages, there is a negative effect through the fall in the workers' share of the surplus.

Note that unemployment benefits policy has not been considered in this comparison, as benefits need to be reduced in order to reduce unemployment. This is so because a reduction in $\rho$ reduces the workers' threat point and hence 
reduces their wages. Consequently match profits rise and firms open more vacancies. Thus this is a policy where unemployment and public expenses fall at the same time.

\subsection{Budget Constraints}

The analysis so far has focused on changes in one policy instrument at a time, comparing policy moves that have the same cost. It shall now look at the effects of multiple changes and considerations related to the government budget constraint. In general the government has the following constraint:

$$
\tau_{N}-\tau_{W} s+\tau_{\Theta} \widetilde{\Gamma}+\rho s\left(\frac{U}{N}\right)=T
$$

where:

$$
\widetilde{\Gamma}=\frac{\Theta}{1+\gamma}\left(\psi\left(\frac{V}{N}\right)+(1-\psi)\left(\frac{M}{N}\right)\right)^{1+\gamma}
$$

The constraint is written in terms of output. It says that government expenditures less revenues total some amount $T \lessgtr 0$. Thus, for example, the sum of the employment subsidy, the hiring subsidy and unemployment benefit payments, less wage tax receipts, has to equal $T$.

The government may combine equation (18) with equations (10) and (12) to solve for a targeted labor market outcome, such as the rate of unemployment $\frac{U}{N}$, and for the value of the policy instruments. As the government has four instruments, it can set two of them arbitrarily and solve the three equations for the other two instruments and for the vacancy rate $\frac{V}{N}$ (assuming that it is the unemployment rate which is targeted). Note that this solution entails firm's optimization, and that with changes in policy, firms re-optimize. Thus the government can construct schedules for the values of the policy instruments, given an unemployment target, that withstand the Lucas critique.

This analysis may be undertaken in numerous ways. Here the focus is placed on one real-world relevant case whereby policy aims at lowering the unemployment rate. Denoting by 0 the steady state value before the change and by 1 the value after the change, the following equation captures the above constraint, assuming a fixed $T$ :

$$
\left(\tau_{N}^{1}-\tau_{N}^{0}\right)-\left(\tau_{W}^{1} s^{1}-\tau_{W}^{0} s^{0}\right)+\left(\tau_{\Theta}^{1} \widetilde{\Gamma}^{1}-\tau_{\Theta}^{0} \widetilde{\Gamma}^{0}\right)+\left(\rho^{1} s^{1}\left(\frac{U}{N}\right)^{1}-\rho^{0} s^{0}\left(\frac{U}{N}\right)^{0}\right)=0
$$


The analysis is implemented as follows: the baseline values of Table 1 are taken as the values for the variables and the parameters at steady state 0 ; an unemployment target $\left(\frac{U}{N}\right)^{1}$ is set; then (10), (12) and (19) are used to solve for $\left(\frac{V}{N}\right)^{1}$ and two policy instruments, setting the other two at arbitrary levels. Intuitively the idea is to set the policy instruments so that the vacancy creation curve will intersect the Beveridge curve at the desired unemployment rate and at the same time satisfy the budget constraint. As two out of the four policy instruments may be set arbitrarily, a full taxonomy is too long to report. Table 4 reports the case where two instruments are left at their baseline values and the other two are set so that the rate of unemployment $\frac{U}{L}$ drops by one percentage point from $7.2 \%$ at the baseline to $6.2 \%$. The table reports the outcome for all endogenous variables at the steady state.

Table 4

The key numbers in the table - indicated in bold in the top two rows - are the values of the two policy instruments under consideration. These come from the solution to the set of equations elaborated above, i.e. they are solved endogenously. In all cases policy encourages vacancy creation raising it from $5.8 \%$ at the baseline to $6.2 \%$. Unemployment falls to its targeted value as the economy moves up the Beveridge curve. Consequently the workers' matching $(P)$ rises and the firms' matching $(Q)$ falls. These values are the same for all cases examined. The change in profits (both per period $\pi$ and the asset values $Q \Phi \pi)$ and the pre-tax labor share $(s)$ varies across cases. This is so because the different policy moves affect the surplus (via $\tau_{N}$ ) and the wage parameters $(\eta$ and $\omega$ ) in different ways.

In three cases (columns 1-3) a hiring subsidy is used to lower marginal costs. The subsidy is financed by an employment tax or by an increase in the wage tax or through a reduction in unemployment benefit payments. For a one percentage point reduction in the unemployment rate a subsidy of around $20 \%$ of hiring costs is needed, financed by tax increases of about $0.5 \%$ of output. Note that unemployment falls in cases 1 and 2 despite the tax increases because the hiring subsidy is more effective than the other tax instruments. In terms of panel (a) of Figure 1 the hiring subsidy makes the marginal cost curve move downwards. The tax increases shift the asset value curve downwards and benefits reduction shift the latter curve upwards. The simulation reveals that the government cannot reduce unemployment using an employment subsidy or a reduction in wage taxes financed by a hiring tax. While allowing for $\tau_{\Theta}<0$ with $\tau_{N}>0$ or $\tau_{W}^{1} s^{1}-\tau_{W}^{0} s^{0}>0$ no such solution was obtained with the baseline model. The reason for this result has again to do with the relative effectiveness of the different policy instruments. 
In three cases (columns 3,4 and 5) unemployment benefit payments are reduced. This in itself operates to reduce unemployment. However maintaining the budget constraint (revenue-neutrality) means increasing expenditures (either on hiring or employment subsidies or reducing the wage tax). Note that the policy move considered in column $5-$ simultaneous reduction in benefits and in wage taxes - is one that is often advocated. Note too that because the employment subsidy and the reduction in the wage tax (columns 4 and 5) are not very effective policy moves, a bigger reduction in benefit payments is required in these cases relative to the case where a hiring subsidy is used (column 3). In the former, a reduction of 13 percentage points in the replacement ratio is needed, while in the latter a 2 percentage point reduction is sufficient.

\section{Conclusions}

The paper presented an empirically-grounded model of the effects of policy in the presence of labor market frictions. The calibrated model, using VAR estimates of the dynamics of the exogenous variables, fits both the data averages of the variables and their business cycle moments.

A simulation analysis has quantified the effects of policy measures on the cyclical behavior and steady state values of the rates of unemployment and vacancies, their duration, firms' match profits (both per period and the expected present value) and workers' wages. The main conclusions from the quantitative analysis are:

(i) Hiring costs and unemployment benefits have substantial effects on labor market outcomes. Thus, provision of hiring subsidies or reduction in benefits have important consequences for the major variables. These results are consistent (though they do not constitute direct evidence or proof) with the view that high European unemployment is due to high hiring costs and generous unemployment benefits. It was shown how unemployment may be reduced through the joint use of hiring subsidies and reduction of unemployment benefits under a given budget constraint.

(ii) Employment subsidies or wage tax reductions are not very effective policy instruments. The share of the workers in the wage bargain is important for the effectiveness of these policy measures.

(iii) Policy has effects on the stochastic behavior of key variables. Measures that reduce unemployment also reduce its persistence and increase the volatility of vacancies. 


\section{Appendix A \\ The Derivation of the Log-Linear Dynamic System and Its Solution}

In order to define the dynamics of the model, it is log-linearized around its steady state. The approach consists of the following steps. Using the F.O.C, the non-stochastic steady state is characterized in equations (10) and (11). The deterministic version of the F.O.C of the firm's problem, including the flow equation for employment, is linearly approximated in the neighborhood of this steady state. This yields a first-order, linear, difference equation system, which solution gives the dynamic path of the control and the endogenous state variables as a function of a sequence of the exogenous variables. Working from a certainty equivalence perspective, the deterministic sequences for the exogenous variables are then replaced with the conditional expectations at time $t$ using the stochastic processes given by equations (6). The resulting dynamic system is given by equation (14). This dynamic system is solved by the regular methods of difference equations (see for example Blanchard and Kahn (1980)). Saddle path stability holds true if one of the characteristic roots of this system is above 1 and one is below 1 in absolute value. This condition may be re-written as $\operatorname{det} B-\operatorname{tr} B+1<0$. For each case simulated it was verified that this condition holds true.

The solution yields a difference equation for $\widehat{n}_{t+1}$ given an initial $\widehat{n}_{0}$ that is consistent with the transversality condition and is expressed by:

$$
\widehat{n}_{t+1}=v_{1} \widehat{n}_{t}+\kappa_{1} x_{t}+\kappa_{2} \sum_{j=0}^{\infty} v_{2} x_{t+j+1}
$$

where $\kappa_{1}$ and $\kappa_{2}$ are functions of the underlying parameters, and $x_{t}=\left[\begin{array}{c}\widehat{G}_{t}^{X} \\ \widehat{G}_{t}^{L} \\ \widehat{\beta}_{t}\end{array}\right]$

Recall that the stochastic behavior of the exogenous variables is given by $x_{t+1}=\prod x_{t}+\Sigma_{t+1}$. Note that the parameters $\kappa_{1}$ and $\kappa_{2}$ include products of the exogenous variables VAR coefficient matrix $\Pi$ as the sequence of future values of $x$ is replaced by their expected values using (6).

In order to characterize the properties of the dynamic path of $\widehat{n}$ in the nonstochastic case, set all exogenous variables equal to their steady state values and so the dynamics are given by:

$$
\widehat{n}_{t+1}=v_{1} \widehat{n}_{t}
$$

\section{Appendix B}




\section{Data: Sources and Definitions}

All data are quarterly for the periods noted. The following table lists definitions and original sources.

\begin{tabular}{|l|l|}
\hline Series & Definition and Sources \\
\hline \hline$F$ & Real business sector GDP \\
\hline & CBS, 1964-1995 \\
\hline$L, N, U$ & Labor force, business sector employment, and unemployment \\
\hline & CBS, 1960-1995 \\
\hline$r$ & Real interest rate on bank credit \\
\hline & $=$ nominal rate, deflated by business sector GDP deflator inflation \\
\hline & BOI, 1972-1995 \\
\hline$V$ & Vacancies \\
\hline & ES, 1975-1989 \\
\hline$M$ & Filled Vacancies \\
\hline & ES, 1975-1989 \\
\hline
\end{tabular}

\section{Notes:}

$\mathrm{CBS}=$ Central Bureau of Statistics

BOI $=$ Bank of Israel

$\mathrm{ES}=$ Employment Service 


\section{References}

[1] Blanchard, Olivier J. and Charles Kahn, 1980. "The Solution of Linear Difference Models Under Rational Expectations," Econometrica 48(5), 1305-1311.

[2] Diamond, Peter A., 1982a. "Aggregate Demand Management in Search Equilibrium," Journal of Political Economy 90(5), 881-894.

[3] Diamond, Peter A., 1982b. "Wage Determination and Efficiency in Search Equilibrium," Review of Economic Studies 49, 761-782.

[4] Hall, Robert E., 1999. "Labor Market Frictions and Employment Fluctuations," Chapter 17 in John B. Taylor and Michael Woodford (eds.), Handbook of Macroeconomics Vol. 1B, North-Holland, Amsterdam.

[5] Krugman, Paul, 1994. "Past and Prospective Causes for High Unemployment," in: Reducing Unemployment: Current Issues and Policy Options, Federal Reserve Bank of Kansas City,Wyoming.

[6] Millard, Stephen P., and Dale T. Mortensen, 1997. "The Unemployment and Welfare Effects of Labor Market Policy: A Comparison of the USA and the UK," in D.J. Snower and G. de la Dehesa (eds.) Unemployment Policy: Government Options for the Labour Market, Cambridge University Press, Cambridge.

[7] Mortensen, Dale T., 1982. " The Matching Process as a Noncooperative Bargaining Game," in J.J. McCall (ed.) The Economics of Information and Uncertainty, University of Chicago Press, Chicago.

[8] Mortensen, Dale T. and Christopher A. Pissarides, 1999a. "Job Reallocation, Employment Fluctuations, and Unemployment," Chapter 18 in John B. Taylor and Michael Woodford (eds.), Handbook of Macroeconomics Vol. 1B, North-Holland, Amsterdam.

[9] Mortensen, Dale T. and Christopher A. Pissarides, 1999b. "Unemployment Responses to 'Skill Biased' Technological Shocks: the Role of Labour Market Policy," The Economic Journal 109, 242-265.

[10] OECD,1994. The OECD Jobs Study, Paris.

[11] Petrongolo Barbara and Christopher A. Pissarides, 2001. "Looking into the Black Box: A Survey of the Matching Function," Journal of Economic Literature 39,2 . 
[12] Pissarides, Christopher A., 1985. "Short-Run Dynamics of Unemployment, Vacancies and Real Wages," American Economic Review 75, 676-690.

[13] Pissarides, Christopher A., 1998. "The Impact of Employment Tax Cuts on Unemployment and Wages; The Role of Unemployment Benefits and Tax Structure." European Economic Review 42, 155-183.

[14] Pissarides, Christopher A., 2000. Equilibrium Unemployment Theory, 2nd edition, MIT Press, Cambridge.

[15] Snower, Dennis J., and Guillermo de la Dehesa (eds.), 1997. Unemployment Policy: Government Options for the Labour Market, Cambridge University Press, Cambridge.

[16] Yashiv, Eran, 2000a. "The Determinants of Equilibrium Unemployment," American Economic Review 90 (5), 1297-1322.

[17] Yashiv, Eran, 2000b. "Hiring As Investment Behavior," Review of Economic Dynamics 3, 486-522. 
Table 1

Baseline Model

a. Parameters

\begin{tabular}{lll}
\hline function & symbol & value \\
\hline \hline hiring & $\Theta$ & $1,015,940$ \\
& $\gamma$ & 4.4 \\
& $\psi$ & 0.3 \\
separation & $\delta$ & 0.0406 \\
matching & $\mu$ & 0.73 \\
& $\sigma$ & 0.3 \\
wage & $\xi$ & 0.17 \\
production & $\alpha$ & 0.68 \\
non-pecuniary income & $z$ & 0.09
\end{tabular}

b. Exogenous Variables

\begin{tabular}{lll}
\hline variable & symbol & value \\
\hline \hline interest rate & $r$ & 0.01 \\
productivity growth (gross rate) & $G^{X}$ & 1.005 \\
labor force growth (gross rate) & $G^{L}$ & 1.006
\end{tabular}

c. Policy Variables

\begin{tabular}{lll}
\hline policy measure & symbol & value \\
\hline \hline hiring subsidies & $\tau_{\Theta}$ & 0 \\
employment subsidy & $\tau_{N}$ & 0 \\
wage tax & $\tau_{W}$ & 0.28 \\
replacement ratio & $\rho$ & 0.4
\end{tabular}

d. Steady State Values

\begin{tabular}{lll}
\hline & symbol & value \\
\hline \hline unemployment rates & $\frac{U}{N}$ & 0.0776 \\
& $\frac{U}{E}$ & 0.0720 \\
vacancy rate & $\frac{V}{N}$ & 0.0582 \\
matching rate & $\frac{M}{N}$ & 0.0466 \\
workers' matching rate & $P=\frac{M}{V}$ & 0.60 \\
firms' matching rate & $Q=\frac{M}{V}$ & 0.80 \\
wage share & $s=\frac{W N}{F}$ & 0.67 \\
per-period profits & $\pi$ & 0.094 \\
expected asset value of the match & $Q \Phi \pi$ & 1.65
\end{tabular}


e. Dynamic Path $\widehat{n}_{t+1}=v_{1} \widehat{n}_{t}$

\begin{tabular}{|l|l|}
\hline$v_{1}$ & 0.8548 \\
\hline half-life & 4.42 \\
\hline
\end{tabular}

half life=the number of quarters in which half the percentage deviation from steady state is eliminated.

\section{f. Business Cycle Dynamics}

\begin{tabular}{llll}
\hline & & model & data \\
\hline \hline persistence & $\rho\left(\widehat{n}_{t}, \widehat{n}_{t-1}\right)$ & 0.97 & 0.95 \\
co-movement & $\rho\left(\widehat{u}_{t}, \widehat{v}_{t)}\right.$ & -0.63 & -0.47 \\
& $\rho\left(\widehat{s}_{t}, \widehat{n}_{t)}\right.$ & 0.53 & 0.27 \\
& $\rho\left(\widehat{n}_{t}, \widehat{G}_{t}^{X}\right)$ & 0.01 & -0.01 \\
volatility & $\frac{\operatorname{std} \widehat{v}}{\operatorname{st} \hat{n}}$ & 9.6 & 17.8 \\
& $\frac{\operatorname{std} s}{\operatorname{std} \hat{n}}$ & 19.2 & 1.8
\end{tabular}

\section{Notes:}

1. Calibrated parameters: these are based on the structural estimates reported in Yashiv (2000 a,b) except the scale parameters of the hiring cost function $(\Theta)$ and of the matching function $(\mu)$ which are set so that the solution of the system will yield the sample average values of $\frac{U}{N}$ and $\frac{V}{N}$ discussed below.

2. Exogenous variables: Labor force growth - excluding government employment - was $0.6 \%$ per quarter in the pre-1990s period, before immigration temporarily raised this number. We thus take $G^{L}=1.006$. This allows us to derive the rate of separation $\delta=\frac{M}{N}-\left(G^{L}-1\right)$ at $4.1 \%$. For the gross rate of business sector labor productivity growth $G^{X}$ we use NIPA and LFS data in the period 1980-1995 and get 1.005. For the real rate of interest $r$ there are discrepancies between different data series: use of the rate of growth of non-durable consumption (the series normally used in general equilibrium models) yields an average of $0.8 \%$ per quarter in the period post-1980. Use of the most reliable market interest rate series - the rate charged by commercial banks on loans deflated by GDP deflator inflation yields an average of $1.3 \%$ per quarter. In studies of the U.S. economy a rate of $1 \%$ per quarter is a prevalent value. We take the latter value as it is also a reasonable approximation of the average of the two series mentioned.

3. Policy parameters: the numbers are average policy parameter values, based on the data. 
4. Steady state values of endogneous variables. For $\frac{U}{L}$ we take the average unemployment rate (in LFS data) from 1980 till 1995. We use this period because the post-1980s period was markedly different than the preceding period and in 1995 LFS definitions were changed. From this rate $(7.2 \%)$ of $\frac{U}{L}$ we deduce the rate $\frac{U}{N}$ at $7.8 \%$. We take LFS data on unemployment duration, with an average of approximately 20 weeks, and set $P=0.60$. The analog matching rate for firms is available from ES data on vacancies and is set to be $Q=0.8$. We use the steady state relationship $\frac{P}{Q}=\frac{V}{U}$ and the values of $\frac{U}{N}, P$ and $Q$ to set $\frac{V}{N}$ at $5.8 \%$ per quarter. As a further check on the validity of the latter figure note that the average of $\frac{V}{N}$ in the data is $6 \%$. This allows us to derive $\frac{M}{N}=Q \frac{V}{N}$ at $4.7 \%$ per quarter. The remaining numbers are obtained from the solution of the model in the steady state. 
Table 2

Policy Effects

\title{
I Hiring Subsidies/Taxes
}

\author{
a. Steady State
}

\begin{tabular}{llllll}
\hline & symbol & baseline (\%) & $\tau_{\theta}=42.92 \%$ & $\tau_{\theta}=42.92 \%$ & $\tau_{\theta}=-72.16$ \\
\hline & & & & $\delta=0.045$ & \\
\hline \hline unemployment rates & $\frac{U}{N}$ & 7.8 & 5.7 & 7.8 & 10.8 \\
& $\frac{U}{E}$ & 7.2 & 5.4 & 7.2 & 9.7 \\
vacancy rate & $\frac{V}{N}$ & 5.8 & 6.7 & 6.6 & 5.1 \\
workers' matching rate & $P=\frac{M}{U}$ & 60 & 82 & 66 & 43 \\
firms' matching rate & $Q=\frac{M}{V}$ & 80 & 70 & 77 & 92 \\
wage share & $s=\frac{W N}{F}$ & 67.00 & 67.25 & 66.98 & 66.66 \\
per period match profits & $\pi$ & 9.4 & 7.0 & 9.4 & 12.6 \\
match asset value & $Q \Phi \pi$ & 165 & 108 & 145 & 255
\end{tabular}

\section{b. Dynamic Path}

\begin{tabular}{lllll}
\hline & baseline & $\tau_{\theta}=42.92 \%$ & $\tau_{\theta}=42.92 \% ; \delta=0.045$ & $\tau_{\theta}=-72.16 \%$ \\
\hline \hline$v_{1}$ & 0.85 & 0.80 & 0.84 & 0.90 \\
half-life & 4.4 & 3.1 & 4.1 & 6.3
\end{tabular}

c. Business Cycle Features

\begin{tabular}{llllll}
\hline & & baseline & $\tau_{\theta}=42.92 \%$ & $\tau_{\theta}=42.92 \% ; \delta=0.045$ & $\tau_{\theta}=-72.16 \%$ \\
\hline \hline persistence & $\rho\left(\widehat{n}_{t}, \widehat{n}_{t-1}\right)$ & 0.970 & 0.958 & 0.968 & 0.979 \\
co-movement & $\rho\left(\widehat{u}_{t}, \widehat{v}_{t}\right)$ & -0.63 & -0.65 & -0.65 & -0.61 \\
& $\rho\left(\widehat{s}_{t}, \widehat{n}_{t}\right)$ & 0.53 & 0.59 & 0.57 & 0.47 \\
\multirow{3}{*}{ volatility } & $\rho\left(\widehat{n}_{t}, \widehat{G}_{t}^{X}\right)$ & 0.01 & 0.01 & 0.01 & 0.01 \\
& $\frac{\operatorname{std} \widehat{v}}{\operatorname{std} \widehat{n}}$ & 9.6 & 11.8 & 9.3 & 7.9 \\
& $\frac{\operatorname{std} s}{\operatorname{std} \widehat{n}}$ & 19.2 & 24.4 & 15.4 & 15.3
\end{tabular}


Table 2

II Employment Subsidies/Taxes

\section{a. Steady State}

\begin{tabular}{lllll}
\hline & symbol & baseline (\%) & $\tau_{N}=1 \%$ & $\tau_{N}=-1 \%$ \\
\hline \hline unemployment rates & $\frac{U}{N}$ & 7.76 & 7.69 & 7.83 \\
& $\frac{U}{V}$ & 7.20 & 7.14 & 7.26 \\
vacancy rate & $\frac{V}{N}$ & 5.82 & 5.84 & 5.80 \\
workers' matching rate & $P=\frac{M}{U}$ & 60.0 & 60.5 & 59.4 \\
firms' matching rate & $Q=\frac{M}{V}$ & 80.0 & 79.7 & 80.3 \\
wage share & $s=\frac{W N}{F}$ & 67.0 & 67.7 & 66.2 \\
per-period match profits & $\pi$ & 9.40 & 9.48 & 9.34 \\
expected asset value of the match & $Q \Phi \pi$ & 165.4 & 165.9 & 164.8
\end{tabular}

variations in the bargaining parameter

\begin{tabular}{lllll}
\hline & $\tau_{N}=1 \%$ & $\tau_{N}=-1 \%$ & $\tau_{N}=1 \%$ & $\tau_{N}=-1 \%$ \\
& $\xi=0.1$ & $\xi=0.1$ & $\xi=0.3$ & $\xi=0.3$ \\
\hline \hline$\frac{U}{L}$ & 7.10 & 7.31 & 7.17 & 7.23 \\
$s$ & 67.7 & 66.3 & 67.7 & 66.3 \\
$Q \Phi \pi$ & 166.3 & 164.4 & 165.6 & 165.1
\end{tabular}




\section{b. Dynamic Path}

\begin{tabular}{llll}
\hline & baseline & $\tau_{N}=1 \%$ & $\tau_{N}=-1 \%$ \\
\hline \hline$v_{1}$ & 0.8548 & 0.8535 & 0.8561 \\
half-life & 4.42 & 4.37 & 4.46
\end{tabular}

variations in the bargaining parameter

\begin{tabular}{lllllll}
\hline & baseline & $\tau_{N}=1 \%$ & $\tau_{N}=-1 \%$ & baseline & $\tau_{N}=1 \%$ & $\tau_{N}=-1 \%$ \\
& $\xi=0.1$ & $\xi=0.1$ & $\xi=0.1$ & $\xi=0.3$ & $\xi=0.3$ & $\xi=0.3$ \\
\hline \hline$v_{1}$ & 0.8626 & 0.8605 & 0.8649 & 0.8470 & 0.8463 & 0.8477 \\
half-life & 4.69 & 4.61 & 4.78 & 4.17 & 4.15 & 4.19
\end{tabular}

\section{c. Business Cycle Features}

\begin{tabular}{lllll}
\hline & & baseline & $\tau_{N}=1 \%$ & $\tau_{N}=-1 \%$ \\
\hline \hline persistence & $\rho\left(\widehat{n}_{t}, \widehat{n}_{t-1}\right)$ & 0.9703 & 0.9700 & 0.9706 \\
co-movement & $\rho\left(\widehat{u}_{t}, \widehat{v}_{t}\right)$ & -0.628 & -0.629 & -0.628 \\
& $\rho\left(\widehat{s}_{t}, \widehat{n}_{t}\right)$ & 0.529 & 0.531 & 0.527 \\
& $\rho\left(\widehat{n}_{t}, \widehat{G}_{t}^{X}\right)$ & 0.01 & 0.01 & 0.01 \\
volatility & $\frac{\operatorname{std} \hat{v}}{\operatorname{stc} \hat{\widehat{n}}}$ & 9.6 & 9.7 & 9.6 \\
& $\frac{\operatorname{std} s}{\operatorname{std} \widehat{n}}$ & 19.2 & 19.4 & 19.1
\end{tabular}

variations in the bargaining parameter

\begin{tabular}{lllllll}
\hline & baseline & $\tau_{N}=1 \%$ & $\tau_{N}=-1 \%$ & baseline & $\tau_{N}=1 \%$ & $\tau_{N}=-1 \%$ \\
& $\xi=0.1$ & $\xi=0.1$ & $\xi=0.1$ & $\xi=0.3$ & $\xi=0.3$ & $\xi=0.3$ \\
\hline \hline$\frac{\operatorname{std} \widehat{v}}{\operatorname{std} \widehat{\widehat{r}}}$ & 9.47 & 9.56 & 9.37 & 9.74 & 9.77 & 9.72 \\
$\rho\left(\widehat{n}_{t}, \widehat{n}_{t-1}\right)$ & 0.9720 & 0.9716 & 0.9725 & 0.9684 & 0.9683 & 0.9686 \\
$\rho\left(\widehat{u}_{t}, \widehat{v}_{t)}\right.$ & -0.643 & -0.644 & -0.642 & -0.613 & -0.614 & -0.613
\end{tabular}

Note: the subsidy and the tax are $1 \%$ of output each. 
Table 2

III Wage taxes

a. Steady State

\begin{tabular}{lllll}
\hline & & baseline & $\tau_{W}=26.5 \%$ & $\tau_{W}=29.5 \%$ \\
\hline \hline unemployment rates & $\frac{U}{N}$ & 7.76 & 7.72 & 7.80 \\
& $\frac{U}{L}$ & 7.20 & 7.16 & 7.24 \\
vacancy rate & $\frac{V}{N}$ & 5.82 & 5.83 & 5.80 \\
workers' matching rate & $P=\frac{M}{U}$ & 60.0 & 60.3 & 59.7 \\
firms' matching rate & $Q=\frac{M}{V}$ & 80.0 & 79.8 & 80.2 \\
wage share & $s=\frac{W N}{F}$ & 67.000 & 66.996 & 67.005 \\
per-period match profits & $\pi$ & 9.41 & 9.45 & 9.37 \\
expected asset value of the match & $Q \Phi \pi$ & 165.37 & 165.73 & 165.03
\end{tabular}

variations in the bargaining parameter

\begin{tabular}{lllll}
\hline & $\tau_{W}=26.5 \%$ & $\tau_{W}=29.5 \%$ & $\tau_{W}=26.5 \%$ & $\tau_{W}=29.5 \%$ \\
& $\xi=0.1$ & $\xi=0.1$ & $\xi=0.3$ & $\xi=0.3$ \\
\hline \hline$\frac{U}{L}$ & 7.07 & 7.34 & 7.18 & 7.22 \\
$S$ & 66.984 & 67.017 & 66.997 & 67.003 \\
$Q \Phi \pi$ & 166.60 & 164.08 & 165.60 & 165.15
\end{tabular}




\section{b. Dynamic Path}

\begin{tabular}{|l|l|l|l|l|}
\hline & baseline & $\tau_{W}=26.5 \%$ & $\tau_{W}=29.5 \%$ \\
\hline$v_{1}$ & 0.8548 & 0.8541 & 0.8558 \\
\hline half-life & 4.42 & 4.39 & 4.45 \\
\hline
\end{tabular}

variations in the bargaining parameter

\begin{tabular}{lllllll}
\hline & baseline & $\tau_{W}=26.5 \%$ & $\tau_{W}=29.5 \%$ & baseline & $\tau_{W}=26.5 \%$ & $\tau_{W}=29.5 \%$ \\
& $\xi=0.1$ & $\xi=0.1$ & $\xi=0.1$ & $\xi=0.3$ & $\xi=0.3$ & $\xi=0.3$ \\
\hline \hline$v_{1}$ & 0.8626 & 0.8599 & 0.8656 & 0.8470 & 0.8464 & 0.8476 \\
half-life & 4.69 & 4.59 & 4.80 & 4.17 & 4.16 & 4.19
\end{tabular}

\section{c. Business Cycle Features}

\begin{tabular}{lllll}
\hline & & baseline & $\tau_{W}=26.5 \%$ & $\tau_{W}=29.5 \%$ \\
\hline \hline persistence & $\rho\left(\widehat{n}_{t}, \widehat{n}_{t-1}\right)$ & 0.9703 & 0.9701 & 0.9705 \\
co-movement & $\rho\left(\widehat{u}_{t}, \widehat{v}_{t}\right)$ & -0.628 & -0.629 & -0.628 \\
& $\rho\left(\widehat{s}_{t}, \widehat{n}_{t}\right)$ & 0.529 & 0.530 & 0.528 \\
\multirow{4}{*}{ volatility } & $\rho\left(\widehat{n}_{t}, \widehat{G}_{t}^{X}\right)$ & 0.01 & 0.01 & 0.01 \\
& $\frac{\operatorname{std} \widehat{v}}{\operatorname{std} \widehat{n}}$ & 9.60 & 9.64 & 9.57 \\
& $\frac{\operatorname{std} s}{\operatorname{std} \widehat{n}}$ & 19.23 & 19.49 & 18.95
\end{tabular}

variations in the bargaining parameter

\begin{tabular}{lllllll}
\hline & baseline & $\tau_{W}=26.5 \%$ & $\tau_{W}=29.5 \%$ & baseline & $\tau_{W}=26.5 \%$ & $\tau_{W}=29.5 \%$ \\
& $\xi=0.1$ & $\xi=0.1$ & $\xi=0.1$ & $\xi=0.3$ & $\xi=0.3$ & $\xi=0.3$ \\
\hline \hline$\frac{\operatorname{std} \hat{v}}{\operatorname{std} \widehat{r}}$ & 9.47 & 9.58 & 9.34 & 9.74 & 9.77 & 9.72 \\
$\rho\left(\widehat{n}_{t}, \widehat{n}_{t-1}\right)$ & 0.9720 & 0.9714 & 0.9727 & 0.968 & 0.968 & 0.969 \\
$\rho\left(\widehat{u}_{t}, \widehat{v}_{t}\right)$ & -0.643 & -0.645 & -0.642 & -0.613 & -0.614 & -0.613
\end{tabular}

Note: the subsidy is $1 \%$ of output i.e. the tax reduction is $\left(\tau_{W} s\right)^{\text {baseline }}$ $\tau_{W} s=0.01$; the tax increase is computed similarly. 
Table 2

IV Unemployment Benefits

a. Steady State

\begin{tabular}{lllll}
\hline & symbol & baseline (\%) & $\rho=17.33 \%$ & $\rho=53.20 \%$ \\
\hline \hline unemployment rates & $\frac{U}{N}$ & 7.8 & 6.1 & 9.7 \\
& $\frac{U}{L}$ & 7.2 & 5.7 & 8.9 \\
vacancy rate & $\frac{V}{N}$ & 5.8 & 6.5 & 5.3 \\
workers' matching rate & $P=\frac{M}{U}$ & 60 & 77 & 48 \\
firms' matching rate & $Q=\frac{M}{V}$ & 80 & 72 & 88 \\
wage share & $s=\frac{W N}{F}$ & 67.00 & 66.77 & 67.16 \\
per-period match profits & $\pi$ & 9.4 & 11.6 & 7.9 \\
expected asset value of the match & $Q \Phi \pi$ & 165 & 183 & 153
\end{tabular}

b. Dynamic Path

\begin{tabular}{llll}
\hline & baseline & $\rho=17.33 \%$ & $\rho=53.20 \%$ \\
\hline \hline$v_{1}$ & 0.8548 & 0.8176 & 0.8828 \\
half-life & 4.42 & 3.44 & 5.56
\end{tabular}

c. Business Cycle Features

\begin{tabular}{lllll}
\hline & & baseline & $\rho=17.33 \%$ & $\rho=53.20 \%$ \\
\hline \hline persistence & $\rho\left(\widehat{n}_{t}, \widehat{n}_{t-1}\right)$ & 0.9703 & 0.9620 & 0.9763 \\
co-movement & $\rho\left(\widehat{u}_{t}, \widehat{v}_{t)}\right.$ & -0.63 & -0.66 & -0.61 \\
& $\rho\left(\widehat{s}_{t}, \widehat{n}_{t)}\right.$ & 0.53 & 0.54 & 0.48 \\
\multirow{4}{*}{ volatility } & $\rho\left(\widehat{n}_{t}, \widehat{G}_{t}^{X}\right)$ & 0.01 & 0.01 & 0.01 \\
& $\frac{\operatorname{std} \widehat{v}}{\operatorname{std} \widehat{n}}$ & 9.6 & 11.2 & 8.4 \\
& $\frac{\operatorname{std} s}{\operatorname{std} \widehat{n}}$ & 19.2 & 27.8 & 13.4
\end{tabular}


Table 3

The Effectiveness of Policy Schemes

\begin{tabular}{|c|c|c|c|c|c|c|c|}
\hline instrument & value & $\frac{U}{L}$ & $P$ & $s$ & $\frac{V}{N}$ & $Q$ & $Q \Phi \pi$ \\
\hline Baseline & & 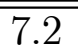 & "60 & "67.00 & 5.82 & 80.0 & 165 \\
\hline$\tau_{\Theta}$ & $42.92 \%$ & 5.4 & 82 & 67.25 & 6.70 & 70 & 108 \\
\hline$\tau_{N}(\xi=0.1)^{2}$ & $1 \%$ & 7.1 & 60.9 & 67.70 & 5.86 & 79.5 & 166.3 \\
\hline$\tau_{N}(\xi=0.17)$ & $1 \%$ & 7.1 & 60.5 & 67.70 & 5.84 & 79.7 & 165.9 \\
\hline$\tau_{N}(\xi=0.3)^{2}$ & $1 \%$ & 7.2 & 60.2 & 67.70 & 5.83 & 79.9 & 165.6 \\
\hline$\tau_{W}(\xi=0.1)^{2}$ & $26.5 \%$ & 7.1 & 61.2 & 66.984 & 5.87 & 79.3 & 166.6 \\
\hline$\tau_{W}(\xi=0.17)$ & $26.5 \%$ & 7.2 & 60.3 & 66.996 & 5.83 & 79.8 & 165.7 \\
\hline$\tau_{W}(\xi=0.3)^{2}$ & $26.5 \%$ & 7.2 & 59.8 & 67.003 & 5.81 & 80.1 & 165.2 \\
\hline instrument & value & \multicolumn{2}{|c|}{ half-life } & $\rho\left(\widehat{n}_{t}, \widehat{n}_{t-1}\right)$ & \multicolumn{2}{|c|}{$\rho\left(\widehat{u}_{t}, \widehat{v}_{t}\right)$} & $\frac{\operatorname{std} \widehat{v}}{\operatorname{std} \widehat{n}}$ \\
\hline "Baseline & & \multicolumn{2}{|c|}{$\bar{c} 4.42$} & (0.970 & \multicolumn{2}{|c|}{-0.63} & 9.6 \\
\hline$\tau_{\Theta}$ & $42.92 \%$ & \multicolumn{2}{|c|}{3.10} & 0.958 & \multicolumn{2}{|c|}{-0.65} & 11.8 \\
\hline$\tau_{N}(\xi=0.1)^{2}$ & $1 \%$ & \multicolumn{2}{|c|}{4.69} & 0.972 & \multicolumn{2}{|c|}{-0.64} & 9.5 \\
\hline$\tau_{N}(\xi=0.17)$ & $1 \%$ & \multicolumn{2}{|c|}{4.37} & 0.970 & \multicolumn{2}{|c|}{-0.63} & 9.7 \\
\hline$\tau_{N}(\xi=0.3)^{2}$ & $1 \%$ & \multicolumn{2}{|c|}{4.15} & 0.970 & \multicolumn{2}{|c|}{-0.61} & 9.8 \\
\hline$\tau_{W}(\xi=0.1)^{2}$ & $26.5 \%$ & \multicolumn{2}{|c|}{4.69} & 0.972 & \multicolumn{2}{|c|}{-0.64} & 9.5 \\
\hline$\tau_{W}(\xi=0.17)$ & $26.5 \%$ & \multicolumn{2}{|c|}{4.39} & 0.970 & \multicolumn{2}{|c|}{-0.63} & 9.6 \\
\hline$\tau_{W}(\xi=0.3)^{2}$ & $26.5 \%$ & \multicolumn{2}{|c|}{4.19} & 0.969 & \multicolumn{2}{|c|}{-0.61} & 9.7 \\
\hline
\end{tabular}

\section{Notes:}

1. The table shows the value of policy instruments corresponding to outlays of $1 \%$ of output (first column) and the resulting value of the key variables and key moments in percentage points.

2. In the cases of $\xi=0.1,0.3$ note that the baseline itself changes (not reported here). 
Table 4

Budget-Constrained Policy Changes

\begin{tabular}{|l|l|l|l|l|l|l|}
\hline & baseline & \multicolumn{1}{c|}{$\mathbf{1}$} & \multicolumn{1}{c|}{$\mathbf{2}$} & \multicolumn{1}{c|}{$\mathbf{3}$} & \multicolumn{1}{c|}{$\mathbf{4}$} & \multicolumn{1}{c}{$\mathbf{5}$} \\
\hline & $\tau_{N}=\tau_{\Theta}=0$ & $\boldsymbol{\tau}_{N}=-0.005$ & $\boldsymbol{\tau}_{W}=0.287$ & $\boldsymbol{\rho}=0.38$ & $\boldsymbol{\rho}=0.27$ & $\boldsymbol{\rho}=0.27$ \\
\hline & $\tau_{W}=0.28 ; \rho=0.4$ & $\boldsymbol{\tau}_{\Theta}=0.24$ & $\boldsymbol{\tau}_{\Theta}=0.24$ & $\boldsymbol{\tau}_{\Theta}=0.20$ & $\boldsymbol{\tau}_{N}=0.009$ & $\boldsymbol{\tau}_{W}=0.267$ \\
\hline$s=\frac{W N}{F}$ & 0.670 & 0.668 & 0.671 & 0.671 & 0.675 & 0.669 \\
\hline$\pi$ & 0.094 & 0.08 & 0.08 & 0.09 & 0.11 & 0.11 \\
\hline$Q \Phi \pi$ & 1.65 & 1.33 & 1.34 & 1.41 & 1.76 & 1.76 \\
\hline
\end{tabular}

In all cases the following obtains:

\begin{tabular}{llll}
\hline & symbol & baseline value & new value \\
\hline \hline unemployment rates & $\frac{U}{N}$ & 0.078 & 0.067 \\
& $\frac{U}{E}$ & 0.072 & 0.062 \\
vacancy rate & $\frac{V}{N}$ & 0.058 & 0.062 \\
matching rate & $\frac{M}{N}$ & 0.047 & 0.047 \\
workers' matching rate & $P=\frac{M}{U}$ & 0.60 & 0.70 \\
firms' matching rate & $Q=\frac{M}{V}$ & 0.80 & 0.75
\end{tabular}




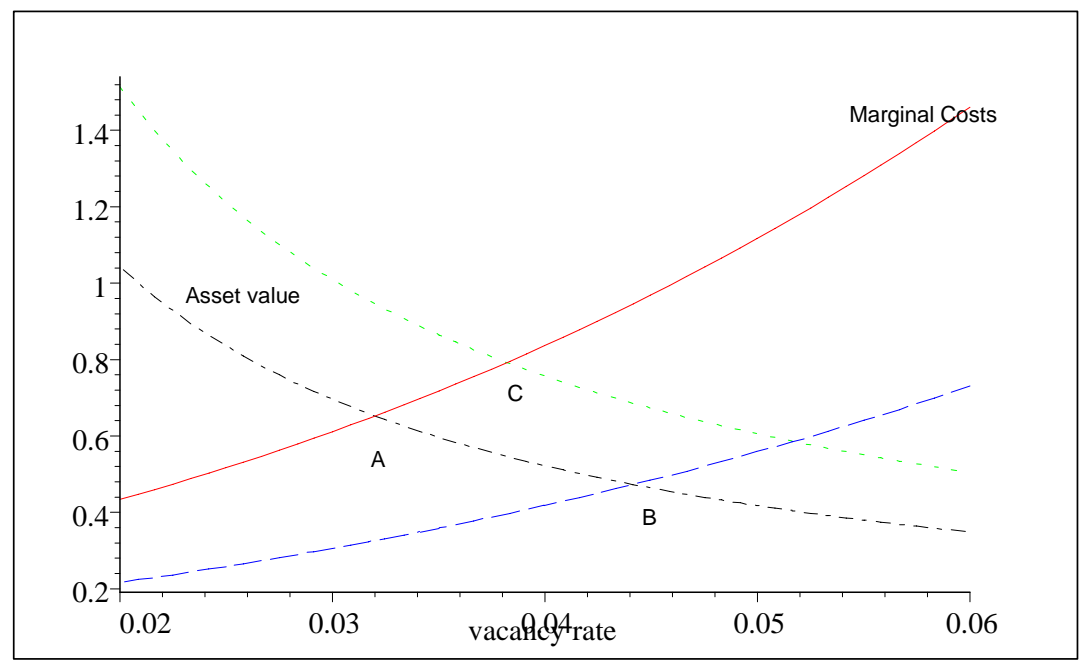

Figure 1a: Marginal Costs and Match Asset Values

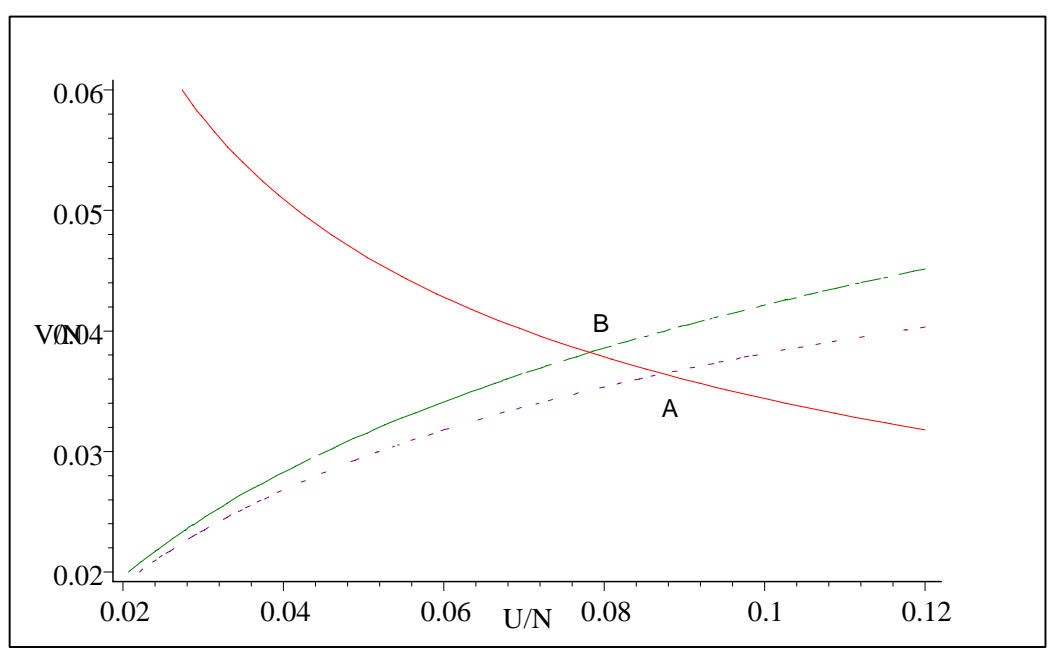

Figure 1b: Unemployment and Vacancy Rates 


\section{IZA Discussion Papers}

No. Author(s)

431

M. Fertig

C. M. Schmidt

432

A. D. Kugler

J. D. Angrist

A. D. Kugler

G. S. Epstein

M. E. Ward
A. Kunze

M. Fertig
A. Voicu

G. Fella

P. Manzini

M. Mariotti
G. Bertola
S. Hochguertel
W. Koeniger

C. W. Sibley

P. P. Walsh

M. Lindahl

K. L. Papps

J. O. Newell

$\begin{array}{ll}444 & \begin{array}{l}\text { R. Lalive } \\ \text { J. Zweimüller }\end{array} \\ 445 & \text { G. S. Epstein } \\ 446 & \text { E. Yashiv }\end{array}$

Title

Area

Date

The Perception of Foreigners and Jews in

6

02/02

Germany - A Structural Analysis of a Large

Opinion Survey

Employment, Wages, and Alcohol Consumption

4

02/02

in Russia: Evidence from Panel Data

Protective or Counter-Productive? Labor Market

3

02/02

Natives

From Severance Pay to Self-Insurance: Effects

4 of Severance Payments Savings Accounts in

Colombia

Perceived Income, Promotion and Incentive

1

Effects

The Evolution of the Early Career Gender Wage 1 Gap

Evaluating Immigration Policy Potentials and Limitations

Employment Dynamics in the Romanian Labor Market: A Markov Chain Monte Carlo Approach

4

$02 / 02$

Does Divorce Law Matter?

02/02

Dealer Pricing of Consumer Credit

7

02/02

Earnings Inequality and Transition: A Regional 4 Analysis of Poland

Estimating the Effect of Income on Health and

3

02/02

Mortality Using Lottery Prizes as Exogenous

Source of Variation in Income

Identifying Functional Labour Market Areas in

New Zealand: A Reconnaissance Study Using

Travel-to-Work Data

Benefit Entitlement and the Labor Market:

6

02/02

Evidence from a Large-Scale Policy Change

Informational Cascades and Decision to Migrate 1

03/02

Macroeconomic Policy Lessons of Labor Market 6

03/02

Frictions

An updated list of IZA Discussion Papers is available on the center's homepage www.iza.org. 